\title{
Techno-economic Assessment of Reserve Service Provision from Microgrids for Resilience Enhancement
}

DOI:

10.1109/PTC.2019.8810678

\section{Document Version}

Accepted author manuscript

Link to publication record in Manchester Research Explorer

\section{Citation for published version (APA):}

Frosinou, A., Zhou, Y., \& Panteli, M. (2019). Techno-economic Assessment of Reserve Service Provision from Microgrids for Resilience Enhancement. In 2019 IEEE PES PowerTech https://doi.org/10.1109/PTC.2019.8810678

\section{Published in:}

2019 IEEE PES PowerTech

\section{Citing this paper}

Please note that where the full-text provided on Manchester Research Explorer is the Author Accepted Manuscript or Proof version this may differ from the final Published version. If citing, it is advised that you check and use the publisher's definitive version.

\section{General rights}

Copyright and moral rights for the publications made accessible in the Research Explorer are retained by the authors and/or other copyright owners and it is a condition of accessing publications that users recognise and abide by the legal requirements associated with these rights.

\section{Takedown policy}

If you believe that this document breaches copyright please refer to the University of Manchester's Takedown Procedures [http://man.ac.uk/04Y6Bo] or contact uml.scholarlycommunications@manchester.ac.uk providing relevant details, so we can investigate your claim.

\section{OPEN ACCESS}




\section{Techno-economic Assessment of Reserve Service Provision from Microgrids for Resilience Enhancement}

\author{
Asimina Frosinou \\ School of Electrical and Electronic \\ Engineering \\ The University of Manchester \\ Manchester, UK \\ asiminafrosinou@gmail.com
}

\author{
Yutian Zhou \\ North West and Yorkshire Energy \\ Consulting \\ Ove Arup \& Partners Ltd \\ Sheffield, UK \\ Yutian.Zhou@arup.com
}

\author{
Mathaios Panteli \\ School of Electrical and Electronic \\ Engineering \\ The University of Manchester \\ Manchester, UK \\ mathaios.panteli@manchester.ac.uk
}

\begin{abstract}
Microgrids' operational flexibility can be exploited for enhancing system resilience to keep the lights on in the vicinity of these microgrids when the main electricity system is disrupted under varying severe contingency events. This work investigates the techno-economic performance of microgrids in this paradigm, whereby providing reserve services becomes a new revenue stream. An optimisation technique using stochastic programming is proposed with the objective to minimise total operational cost. This enables the quantification of capacity contribution to different reserve services considering the uncertainty of contingency events. Without loss of generality, two representative types of microgrids are analysed while varying reserve price. The results show higher reserve prices lead to more capacity contribution, however a clear saturation is observed. The contribution can also be very sensitive to the reserve price varying within certain ranges. In summary, the proposed assessment can inform relevant stakeholders on the microgrids' contribution in reserve service provision.
\end{abstract}

Index Terms-Distributed Energy Resources, Energy Storage, Microgrid, Reserve Service, Resilience.

\section{INTRODUCTION}

Tackling climate change requires the decarbanisation of electricity systems [1]. Meanwhile, due to the unprecedented dependency of our daily activities on the continuous supply of electricity, it is becoming more and more critical to enhance the resilience of electricity systems to possible extreme operating conditions [2] and [3]. In this context, microgrids (MGs) comprising distributed energy resources, such as Combined Heat and Power (CHP), solar photovoltaic (PV) and energy storage, can play a key role in the delivery of a low-carbon as well as resilient electricity system [4]-[6]. This is owing to the capability of MGs to keep the lights on not only for their internal customers but also for those in the vicinity of these MGs, whilst the main electricity system is disrupted during extreme operating conditions (some might have high and prolonged impact) [4].

More specifically, MGs can enhance the resilience of their internal customers by successfully riding through an extreme event [5]. More importantly, owing to the internal generating capability, MGs using generation surplus can accelerate the restoration of their connected network by supplying the customers outside these MGs during a contingency event in the relevant main electricity system [6]. Only a few studies ( [4], [6], [7]) so far have investigated the contribution of MGs to the resilience of a broader network to which these MGs are connected. For instance, Wang et al. [8] and Chen et al. [9] have focused on how to dynamically form MGs to enhance the resilience of the customers inside each of these MGs during distribution network contingency. Similarly, resilience enhancement by multiple MGs as a result of network reconfiguration is studied by different researchers, such as [5], [10]-[18] among others. Further, more recently, Zhou et al. [4] explored resilience provision from MGs at systemlevel, whereby MGs contribute to system resilience via reserve services lasting for different durations. It is important to note that the concept of resilience covers a wide range of characteristics and features, such as the ability to withstand and recover rapidly from disruptions, and to mitigate the impact of High Impact and Low Probability (HILP) events on the frequency and severity of power outages [2]. In this work, as done in [4], MGs can enhance resilience by contributing a constant electricity capacity to their vicinity via reserve services in the event of disruption in main electricity systems. As mentioned earlier, this can effectively expedite the restoration of customers supplied by the network outside these MGs. Thus, this enhances the resilience of that network during extreme operating conditions.

Unlike previous studies, this work goes beyond the generic and well established short-term operating reserve which is for reliability purpose and in preparation for known contingencies. More specifically, reserve services with different durations and that could be called upon in any hour throughout a day are considered and modelled here. On the other hand, exploiting the flexibility of MGs to maximise the benefits to their connected system would most likely to be realised via participating in relevant markets for ancillary services, as explored by Good et al. [11].

On the above premises, a general assessment methodology is proposed in this paper, with the objective to co-optimise the energy consumption and the reserve provision of an MG. Thus, a quantitative understanding of the 
strategic role of MGs can be developed, which will be able to assist policy makers and regulators to design appropriate markets or price signals to engage MGs in enhancing the resilience of the main electricity system.

More specifically, a co-optimisation formulation based on stochastic programming technique is developed in this paper, which takes into account the technical constraints of an MG's energy resources, internal energy consumption and uncertainty in the reserve service (e.g., starting time and duration). Without loss of generality, two representative MGs are modelled in the formulation, i.e. one MG with CHP and thermal energy storage (TES) representing dispatchable generation resources, whereas the other one with PV and electrical energy storage (EES, e.g., battery), representing renewable but uncontrollable generation resources. The objective of the co-optimisation is to minimise the total operational cost of an MG, whilst the contribution to reserve services is maximised by considering a reserve price paid to the MG taking part in the service.

In summary, the objectives of the research work presented in this paper are to develop a general assessment methodology to provide a quantitative understanding of the contribution of MGs to resilience enhancement of the main grid to which they are connected to via reserve services with different durations. Further contributions of the paper also include:

- A co-optimisation using stochastic programming for two representative MGs taking into account technical constraints as well as uncertainty in reserve services.

- A broadened consideration of reserve services with varying durations to account for MGs' contribution to prolonged events with potentially higher impact.

- A sensitivity study on the reserve price fully revealing the economic impact on the contribution from MGs to reserve services and providing insights to policy makers and regulators on the strategic role that MGs can play in resilience enhancement.

The remainder of the paper is organised as follows: Section II presents the proposed generic techno-economic assessment methodology, while Section III provides the cooptimization formulation. The case study application is presented in Section IV. Section V concludes the paper and summarises relevant future work.

\section{TECHNO-ECONOMIC ASSESSMENT METHODOLOGY}

Fig. 1 presents an overview of the proposed technoeconomic assessment framework. As can be seen, the core of the proposed approach is the co-optimization tool of the energy consumption and reserve service provision, based on a stochastic programming technique. This optimization tool takes as inputs varying operational and technical data and constraints, and critically outputs vital information that can be used for the main electricity system planning and $\mathrm{MG}$ resources planning.

More specifically, environmental and weather conditions, such as temperatures, solar irradiance and wind speeds, are not only related to the energy consumption pattern and availability of renewable generation; but they also affect extreme operating conditions, which consequently require

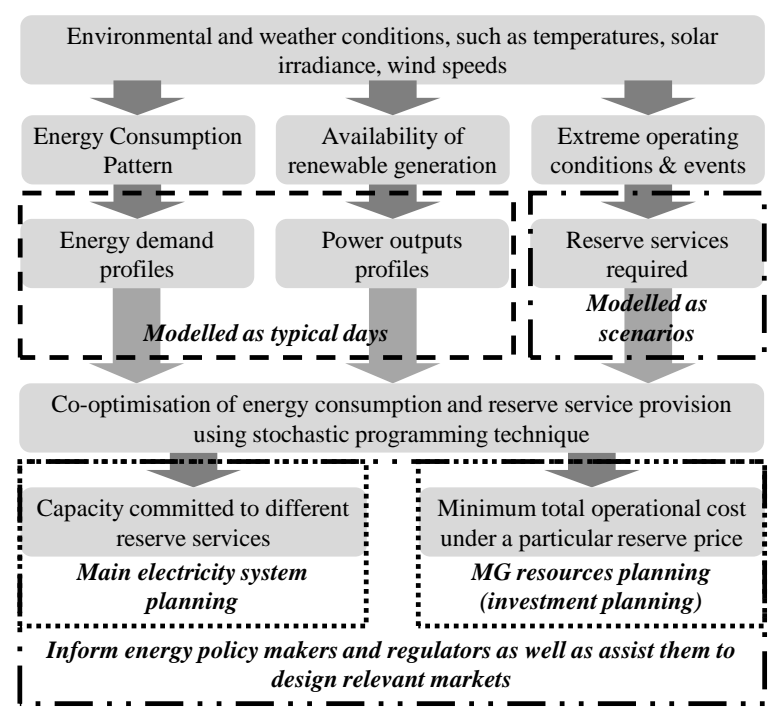

Fig. 1 Flowchart of the proposed techno-economic assessment methodology

reserve services. In the proposed co-optimization, typical day profiles of both energy demand and renewable generation are modelled; meanwhile, different reserve services are modelled as scenarios associated with certain probabilities representing the likelihoods of them happening. Afterwards, the cooptimization determines a day-ahead schedule for the $\mathrm{MG}$ operation with minimum operation cost. Finally, the outputs include different capacities scheduled for reserve services, which can inform main system planning; and the minimum operational cost of MG provides insight into how the reserve prices can affect investment planning of MG. In summary, the acquired information can therefore present a clear picture of the strategic role played by MGs and can assist energy policy makers and regulators to design relevant markets to facilitate the reserve services provided by MGs.

\section{CO-OPTIMISATION FORMULATION}

Two stochastic programming models for a CHP-TES based and a PV-EES based MG are proposed in this paper, which are based on the models presented in [7] and [9]. These two MGs are deemed to be representative, as the CHP-TES based $\mathrm{MG}$ is dispatchable owing to the controllable CHP whereas the PV-EES based MG heavily relies on its EES for operational flexibility.

In terms of reserve service provision, both MGs will only use their generation surplus [4], to provide reserve services during a contingency event. As demonstrated in [4], the capacity surplus is very unlikely to be constant during a contingency event. Thus, the actual capacity contribution to a reserve service should be the minimum capacity surplus during that contingency event. It is worth noting that the MG would store (reserve), in advance, a certain amount of energy (headroom for TES or foot-room for EES) so as to supply its vicinity during a contingency event.

The co-optimisation is formulated in the framework of a day-ahead scheduling for MGs. The objective is to maximize the total daily revenue, while different operational constraints of the two MGs including the heating and electricity demand, the CHP's technical characteristics, the technical parameters 
of TES and EES and the availability of PV generation are all considered. Actually, via maximising the total daily revenue, two conflicting objectives, i.e. the minimisation of an MG's operational cost and the maximisation of its contribution to reserve services, are simultaneously optimised. In essence, it is a multi-objective optimisation [19]. The mathematical formulation is presented below, which consists of the objective functions, technical constraints related to normal operation and the operational constraints during the provision of reserve services.

\section{A. Formulation for CHP-TES based MG}

The objective function maximizes the CHP-TES based MG's revenue as presented in (1). The MG interacts with the main grid by importing $\left(P_{i}^{\mathrm{im}}, \mathrm{kW}\right)$, exporting electricity $\left(P_{i}^{\mathrm{ex}}\right.$, $\mathrm{kW})$ and buying gas $\left(G_{i}, \mathrm{kWh}\right)$ at the price of $\left(c^{\mathrm{im}}, £ / \mathrm{kWh}\right)$, $\left(c^{\mathrm{ex}},\right)$ and $\left(c^{\mathrm{gas}}, \mathfrak{f} / \mathrm{kWh}\right)$ respectively, during normal operation. The counter $i$ is the time steps of the total normal operation duration (I). The MG can also support the main grid during a contingency event by providing reserve services $\left(\operatorname{Res}_{s}^{\min }, \mathrm{kW}\right)$ at the price of $c^{\text {res }}, \mathfrak{f} / \mathrm{kWh}$. It also has to pay for the gas consumed during the reserve service provision $\left(G_{s, t}, \mathrm{kWh}\right)$. In addition, $T$ and $S$ are the numbers of time intervals and scenarios of reserve service throughout a day, respectively; while $t$ and $s$ are the relevant counters. Further, $p_{s}$ and $d_{s}$ (hour) correspond to the probability and duration of a scenario of reserve service, respectively.

$$
\begin{aligned}
& \operatorname{Max}\left\{\sum_{i=1}^{I}\left(-\mathrm{c}^{\mathrm{im}} P_{i}^{\mathrm{im}} \Delta t+\mathrm{c}^{\mathrm{ex}} P_{i}^{\mathrm{ex}} \Delta t-\mathrm{c}^{\mathrm{gas}} G_{i}\right)\right. \\
& \left.+\sum_{s=1}^{S}\left[p_{s} d_{s} \mathrm{c}^{\mathrm{res}} R e s_{s}^{\min }-\sum_{\mathrm{t}=1}^{T} \mathrm{c}^{\mathrm{gas}} G_{s, t}\right]\right\}
\end{aligned}
$$

Electricity generation $\left(P_{i}^{\mathrm{CHP}}, \mathrm{kW}\right)$ and heat cogeneration $\left(H_{i}^{\mathrm{CHP}}, \mathrm{kW}\right)$ scheduled for normal operation are based on the electricity efficiency $\left(\eta^{\mathrm{e}}, \%\right)$ and heat efficiency $\left(\eta^{\mathrm{h}}, \%\right)$ of the CHP unit, as in (2). The electricity generation is constrained by the CHP's electricity capacity $\left(P_{i}^{\mathrm{CHP}, \max }, \mathrm{kW}\right)$, as in (3).

$$
\begin{aligned}
& H_{i}^{\mathrm{CHP}}=P_{i}^{\mathrm{CHP}} \frac{\eta^{\mathrm{h}}}{\eta^{\mathrm{e}}} \\
& P_{i}^{\mathrm{CHP}} \leq P_{i}^{\mathrm{CHP}, \max }
\end{aligned}
$$

The constraint (4) ensures the balance of electricity generation and demand during normal operation, where the internal consumption is denoted by $P_{i}^{\mathrm{L}}, \mathrm{kW}$. The gas consumption by CHP and gas boilers during normal operation is aggregated to $G_{I}, \mathrm{kWh}$ in (5), where the gas boilers heat production is $H_{i}^{\mathrm{GB}}, \mathrm{kW}$ and efficiency is $\eta^{\mathrm{GB}}, \%$.

$$
\begin{gathered}
P_{i}^{\mathrm{im}}+P_{i}^{\mathrm{CHP}}=P_{i}^{\mathrm{L}}+P_{i}^{\mathrm{ex}} \\
G_{i}=\frac{P_{i}^{\mathrm{CHP}}}{\eta^{\mathrm{e}}} \Delta t+\frac{H_{i}^{\mathrm{GB}}}{\eta^{\mathrm{GB}}} \Delta t \\
P_{i}^{\mathrm{im}}, P_{i}^{\mathrm{ex}}, G_{i} \geq 0
\end{gathered}
$$

The MG's capacity contribution $\left(\operatorname{Res}_{s, t}, \mathrm{~kW}\right)$ at each time step within the time window of the reserve service $s$ is limited by the headroom of the CHP unit as seen in (7).

$$
0 \leq \operatorname{Res}_{s, t} \leq P_{i}^{\mathrm{CHP}, \max }-P_{i}^{\mathrm{CHP}}
$$

During the electricity production of the available reserve capacity, the CHP unit cogenerates heat $\left(H_{S, t}^{\mathrm{CHP}}, \mathrm{kW}\right)$. Based on the heat and electricity efficiency of the CHP unit, the produced heat is in (8). As mentioned earlier, the capacity contribution from the MG has to be its minimum capacity surplus $\operatorname{Res}_{s}^{\min }, \mathrm{kW}$ during a reserve service $s$, as in (9)

$$
\begin{aligned}
& H_{s, t}^{\mathrm{CHP}}=\operatorname{Res}_{s, t} \frac{\eta^{\mathrm{h}}}{\eta^{\mathrm{e}}} \\
& \operatorname{Res}_{s}^{\mathrm{min}} \leq \operatorname{Res}_{s, t}
\end{aligned}
$$

The gas consumed during the contingency event consists of the gas need from the gas boiler to cover the MG's heat demand and the CHP unit to provide reserve, as seen in (10), where the gas boilers heat production is $H_{s, t}^{G B}, \mathrm{~kW}$.

$$
\begin{gathered}
G_{s, t}=\frac{H_{s, t}^{G B}}{\eta^{G \mathrm{BB}}} \Delta t+\frac{\operatorname{Res}_{s, t}}{\eta^{\mathrm{e}}} \Delta t \\
G_{s, t} \geq 0
\end{gathered}
$$

TES is an imperative component of this model as it provided flexibility by storing the surplus heat. The State of Charge (SOC) of TES in the current time step $\left(S_{i}^{\text {heat }}, \mathrm{kWh}\right)$ is based not only on the SOC $\left(S_{i-1}^{\text {heat }}, \mathrm{kWh}\right)$ of the previous time step, but also on the heat demand $\left(H_{i}^{\mathrm{Dem}}, \mathrm{kW}\right)$, the heat losses $\left(H_{i}^{\mathrm{L} o s s}, \mathrm{~kW}\right)$, the heat produced from the gas boilers and the CHP units in the current time step, as presented in (12). Furthermore, the heat losses can be calculated from (13). The thermal resistance $\left(R^{\text {therm }}, \mathrm{kWh} / \mathrm{K}\right)$, thermal capacitance $\left(C^{\text {therm }}, \mathrm{K} / \mathrm{kW}\right)$ and the environmental temperature surrounding TES in the current time step $\left(T_{i}, \mathrm{~K}\right)$ are considered. Further, the SOC of the TES has a minimum and maximum limit, as in (14) where $T^{\mathrm{min}}, \mathrm{K}$ and $T^{\mathrm{max}}, \mathrm{K}$ are the minimum and maximum temperatures of TES.

$$
\begin{gathered}
S_{i}^{\text {heat }}=S_{i-1}^{\text {heat }}+\left(H_{i}^{\mathrm{CHP}}-H_{i}^{\text {Dem }}-H_{i}^{\text {Loss }}+H_{i}^{\mathrm{GB}}\right) \Delta t \\
H_{i}^{\text {Loss }}=\left(\frac{S_{i}^{\text {heat }}}{C^{\text {therm }}}-T_{i}\right) / R^{\text {therm }} \\
\left(T^{\text {min }}-T_{i}\right) C^{\text {therm }} \leq S_{i}^{\text {heat }} \leq\left(T^{\text {max }}-T_{i}\right) C^{\text {therm }}
\end{gathered}
$$

The constraint in (15) is for the SOC of the TES during a service $s$. The cogenerated heat $\left(H_{s, t}^{\mathrm{CHP}}, \mathrm{kW}\right)$ due to providing reserve and the heat produced from gas boilers $\left(H_{s, t}^{G B}, \mathrm{~kW}\right)$ in the scenario $s$ have to be considered. At the first-time step of the scenario $s$, the SOC from the normal operation is used as the value of $S_{s, 1}^{\text {heat }}, \mathrm{kWh}$. In this operation condition the environmental temperature is neglected in the calculation of the heat losses $\left(H_{s, t}^{\mathrm{Loss}}, \mathrm{kW}\right)$ for the sake of simplicity. The heat losses are in (16). The limits for the SOC are in (17).

$$
\begin{gathered}
S_{s, t}^{\text {heat }}=S_{s, t-1}^{\text {heat }}+\left(H_{i}^{\mathrm{CHP}}+H_{s, t}^{\mathrm{CHP}}-H_{i}^{\mathrm{Dem}}-H_{s, t}^{\mathrm{Loss}}+H_{i}^{\mathrm{GB}}+H_{s, t}^{G B}\right) \Delta t \\
H_{s, t}^{\mathrm{Loss}}=\frac{S_{s, t}^{\text {heat }}}{C^{\text {therm }} R^{\text {therm }}} \\
\left(T^{\text {min }}-T_{i}\right) C^{\text {therm }} \leq S_{s, t}^{\text {heat }} \leq\left(T^{\text {max }}-T_{i}\right) C^{\text {therm }}
\end{gathered}
$$

\section{B. Formulation for PV-EES based $M G$}

The PV-EES based MG can interact with the distribution 
network by importing $\left(P_{i}^{\mathrm{im}}\right)$ and exporting $\left(P_{i}^{\mathrm{ex}}\right)$ electricity during the normal operation. It can also support the main grid by providing the minimum capacity surplus $\left(\operatorname{Res}_{s}^{\mathrm{min}}\right)$ under contingency scenarios. The objective function in (18) aims to maximise the renewable MG's revenue during all the abovementioned activities.

$$
\begin{aligned}
& \operatorname{Max}\left\{\sum_{i=1}^{I}\left(-\mathrm{c}^{\mathrm{im}} P_{i}^{\mathrm{im}} \Delta t+\mathrm{c}^{\mathrm{ex}} P_{i}^{\mathrm{ex}} \Delta t\right)\right. \\
& \left.+\sum_{s=1}^{s} p_{s} d_{s} \mathrm{c}^{\mathrm{res}} \operatorname{Res}_{s}^{\mathrm{min}}\right\}
\end{aligned}
$$

The constraint in (19) balances the load and generation in the MG during the normal operation. Electricity is generated from PV $\left(P_{i}^{\mathrm{PV}}, \mathrm{kW}\right)$, the discharging of EES $\left(P_{i}^{\mathrm{disch}}, \mathrm{kW}\right)$ or imported from the main grid. This available electricity must cover the internal load $\left(P_{i}^{\mathrm{L}}\right)$, the external demand $\left(P_{i}^{\text {ex }}\right)$, and charge the EES $\left(P_{i}^{\mathrm{charg}}, \mathrm{kW}\right)$.

$$
\begin{gathered}
P_{i}^{\mathrm{im}}+P_{i}^{\mathrm{PV}}+P_{i}^{\mathrm{disch}}=P_{i}^{\mathrm{L}}+P_{i}^{\mathrm{ex}}+P_{i}^{\mathrm{charg}} \\
P_{i}^{\mathrm{im}}, P_{i}^{\mathrm{ex}} \geq 0
\end{gathered}
$$

The PV-EES based MG would not import electricity from the main grid and EES can discharge $\left(P_{s, t}^{\text {disch }}\right)$, during a contingency scenario $s$, and $t$ counts the time interval. The available generation should cover the capacity contribution $\left(\operatorname{Res}_{s, t}\right)$ and the charge of EES $\left(P_{s, t}^{\text {charg }}, \mathrm{kW}\right)$. This new load and generation balance is presented in (21).

$$
P_{i}^{\mathrm{PV}}+P_{s, t}^{\mathrm{disch}}=P_{i}^{\mathrm{L}}+\operatorname{Res}_{s, t}+P_{i}^{\mathrm{ex}}+P_{s, t}^{\mathrm{charg}}
$$

The reserve provided by the MG is its minimum capacity surplus $\left(R e s_{s}^{\min }\right)$ during a contingency event, as in (22).

$$
\operatorname{Res}_{s}^{\mathrm{min}} \leq \operatorname{Res}_{s, t}
$$

The utilization of the EES can yield flexibility and a cheaper operation scheduling. The EES's SOC of the current time step $\left(S_{i}^{\mathrm{EES}}, \mathrm{kWh}\right)$ depends on the the SOC of the previous time step $\left(S_{i-1}^{\mathrm{EES}}, \mathrm{kWh}\right)$ and the EES's charging/discharging power of the current time step, considering also the charging $\left(e f f^{+}, \%\right)$ and discharging (eff, \%) efficiency of the EES, as in (23). The SOC of EES is limited in (24). The binary variable $\left(y_{i}\right)$ is used to express the mode of the EES. When $y_{i}$ is equal to 1, EES is charging and vice versa. The constraint in (25) makes sure that EES can only charge or discharge.

$$
\begin{gathered}
S_{i}^{\mathrm{EES}}=S_{i-1}^{\mathrm{EES}}+P_{i}^{\text {charg }}\left(1-e f f^{+}\right) \Delta t-P_{i}^{\mathrm{disch}}(1-\text { eff }) \Delta t \\
S^{\mathrm{EES}, \text { min }} \leq S_{i}^{\mathrm{EES}} \leq S^{\mathrm{EES}, \max } \\
0 \leq P_{i}^{\text {charg }} \leq P^{\text {charg,max }} y_{i}, 0 \leq P_{i}^{\text {disch }} \leq P^{\text {disch,max }}\left(1-y_{i}\right)
\end{gathered}
$$

During the reserve service provision, EES is modelled in the set of constraints in (26)-(28), following the same principles considered for the normal operation. In the first time step of the contingency event, the EES's SOC $\left(S_{s, t}^{\mathrm{EES}}\right.$, $\mathrm{kWh}$ ) is calcualted based on the EES's SOC of the normal operation in the time step before the contingency occurred.

$$
\begin{aligned}
& S_{s, t}^{\mathrm{EES}}=S_{s, t-1}^{\mathrm{EES}}+P_{s, t}^{\mathrm{charg}}\left(1-\text { eff } f^{+}\right) \Delta t-P_{s, t}^{\text {disch }}(1-\text { eff }) \Delta t \\
& \mathrm{~S}^{\mathrm{EES}, \text { min }} \leq S_{s, t}^{\mathrm{EES}} \leq \mathrm{S}^{\mathrm{EES} \text {,max }} \\
& 0 \leq P_{s, t}^{\text {charg }} \leq P^{\text {charg,max }} y_{s, t}, 0 \leq P_{s, t}^{\text {disch }} \leq P^{\text {disch,max }}\left(1-y_{s, t}\right)
\end{aligned}
$$

\section{CASE STYDY APPLICATION}

This section demonstrates the proposed methodology and formulation using two specific MGs (as introduced in [7]) to demonstrate how varying reserve price can impact on the reserve provision of these MGs, and thus the strategic role of MGs in enhancing the resilience of the main electricity grid.

\section{A. Test MGs and Scenarios for Reserve Services}

According to [7], the CHP-TES based MG is considered to have a CHP unit with $47 \%$ thermal efficiency $\left(\eta^{\mathrm{h}}\right)$ and $37 \%$ electrical efficiency $\left(\eta^{\mathrm{e}}\right)$. The electricity capacity of the CHP unit is $52 \mathrm{~kW}_{\mathrm{e}}$. The maximum and minimum temperatures for the TES are $55^{\circ} \mathrm{C}$ and $80^{\circ} \mathrm{C}$ respectively, while the thermal resistance and capacitance of the TES are $8.42 \mathrm{kWh} / \mathrm{K}$ and $9082.9 \mathrm{~K} / \mathrm{kW}$, respectively. In addition, the size of the TES is $7250 \mathrm{~L}$. The efficiency of the gas boiler is $75 \%\left(\eta^{\mathrm{GB}}\right)$. On the other hand, the PV-EES based MG has a PV capacity of $275 \mathrm{kWp}$ and an EES capacity of $65.85 \mathrm{kWh}$. Similarly, a roundtrip efficiency of $90 \%$ is assumed for both charging and discharging. The heating and electricity demand profiles are the same for both MGs, as described in detail in [6]. In addition, the same PV profiles used in [4] are also adopted here. It needs to be noted that the seasonal characteristics of those profiles are taken into account by considering seven typical days in a year. According to [6], the import and export electricity prices are $£ 0.116 / \mathrm{kWh}$ and $£ 0.056 / \mathrm{kWh}$ respectively; and, the gas price is $£ 0.036 / \mathrm{kWh}$.

In terms of scenarios for reserve services, the duration $\left(d_{s}\right)$ of the possible contingency events in the main grid is assumed to range from 1 hour to 6 hours [4]. Additionally, their probabilities are presented in the Table I, which is based on a generation adequacy assessment carried out for the British system in [12]. Moreover, it is considered that the reserve service could be provided by the MG at any time throughout a day and as the aforementioned profiles are on half-hourly basis, there are 288 (i.e. 6 durations times 48 time steps) scenarios considered in the co-optimisation.

\section{B. Reserve Service Provision from MGs}

This section demonstrates how the CHP-TES based MG and PV-EES based MG contribute to reserve services. The boxplots in Figure 2 are for the CHP-TES based MG and those in Figure 3 are for the PV-EES based MG. They demonstrate the capacity contribution from each $\mathrm{MG}$ to reserve services with respect to their durations. Meanwhile, the scenarios covered by each specific duration include those scenarios of reserve services starting at different times in the seven typical days.

When the reserve price is $£ 0.00451 / \mathrm{kWh}$ (i.e. the UK market price for the provision of short term reserve services [13]), as it is presented in the Fig. 2-a), in all the six cases, the medium value of the capacity contribution from the CHPTES based MG is zero and the third quartile is less than $5 \mathrm{~kW}$. For the extreme contingency event with 6-hour duration, the CHP-TES based MG provides no reserve to the main grid. The capacity contribution changes dramatically, when the

TABLE I Probabilities of capacity shortage events [17]

\begin{tabular}{lllllll}
\hline $\begin{array}{l}\text { Electricity shortage } \\
\text { duration } \mathbf{d}_{\mathbf{s}}(\mathbf{H o u r})\end{array}$ & 1 & 2 & 3 & 4 & 5 & 6 \\
\hline Probability $\mathbf{p}_{\mathbf{s}}(\boldsymbol{\%})$ & 31.02 & 31.78 & 17.77 & 11.79 & 2.63 & 0.78 \\
\hline
\end{tabular}



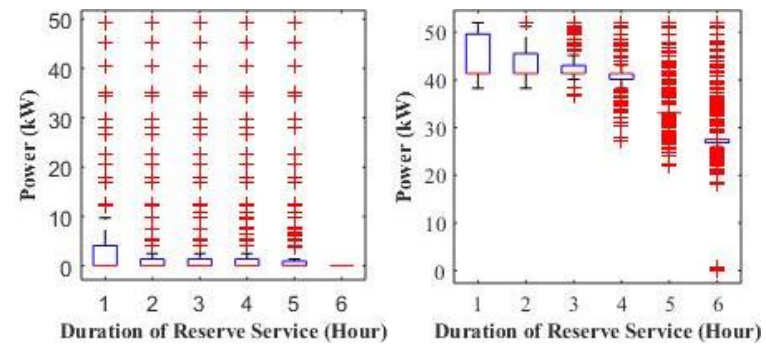

Fig. 2 Boxplot of the reserve service provision from CHP-TES based MG for reserve price signals (a) $£ 0.00451 / \mathrm{kWh}$ (left) and (b) $£ 0.5 / \mathrm{kWh}$ (right).
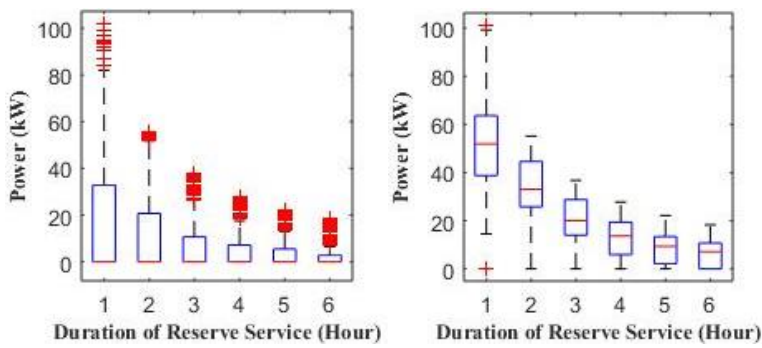

Fig. 3 Boxplot of the reserve service provision from PV-EES based MG for reserve price signals (a) $£ 0.00451 / \mathrm{kWh}$ (left) and (b) $£ 0.5 / \mathrm{kWh}$ (right).

reserve price is $£ 0.5 / \mathrm{kWh}$, as shown in Fig. 2-b). The medium value is almost $42 \mathrm{~kW}$ for 1 to 4 hours reserve service provision and more than $25 \mathrm{~kW}$ for 6 hours.

The PV-EES MG can provide reserve services even if the price is $£ 0.00451 / \mathrm{kWh}$ as seen in Fig. 3-a). For instance, the third quartiles of the capacity contribution are $32 \mathrm{~kW}, 20 \mathrm{~kW}$ and $10 \mathrm{~kW}$ for reserve services lasting 1, 2 and 3 hours; and, those of the capacity contribution are almost $8 \mathrm{~kW}$ and $7 \mathrm{~kW}$ for services with durations of 4 and 5 hours. More importantly, the third quartile for the capacity contribution to the service for extreme events lasting 6 hours can still reach to $4 \mathrm{~kW}$. On the other hand, when the reserve price is $£ 0.5 / \mathrm{kWh}$, as presented in Fig. 3-b), the PV-EES based MG's capacity contribution increased significantly. It has to be highlighted that with higher reserve price, the PV-EES based MG are able to commit an amount of over $10 \mathrm{~kW}$ for the service lasting 6 hours. This means that with proper incentives the MGs with renewable and storage can be relied on for enhancing system resilience to extreme events. Nonetheless, it has to be noted that PV-EES MGs heavily rely on the EES (e.g., batteries) for providing services, as if PV generation were not available EES would become the sole source of electricity.

\section{Sensitivity Study of Reserve Price}

This section focuses on the impact of varying the reserve price by performing a sensitivity analysis. The reserve price is raised from $£ 0.00451 / \mathrm{kWh}$ to $£ 1.0 / \mathrm{kWh}$ gradually. For the sake of clearness, the results focus on the average capacity contributed to reserve services lasting for 1, 2 and 6 hours.

The average capacity contributed by the CHP-TES based MG to 1-hour services and 2-hour services are extremely close to each other, as seen in Fig. 4. The capacity contribution to reserve services rapidly increases from $7 \mathrm{~kW}$ to $17.5 \mathrm{~kW}$, when the reserve price is raised from $£ 0.155 / \mathrm{kWh}$ to $£ 0.16 \mathrm{kWh}$. On the other hand, when the reserve price is overf0.3/kWh, the capacity contribution exhibites a clear saturation. This means that MGs can be very sensitive to the

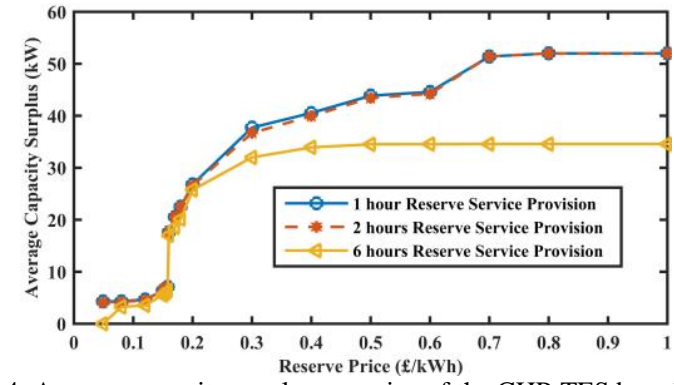

Fig. 4 Average capacity surplus per price of the CHP-TES based MG.

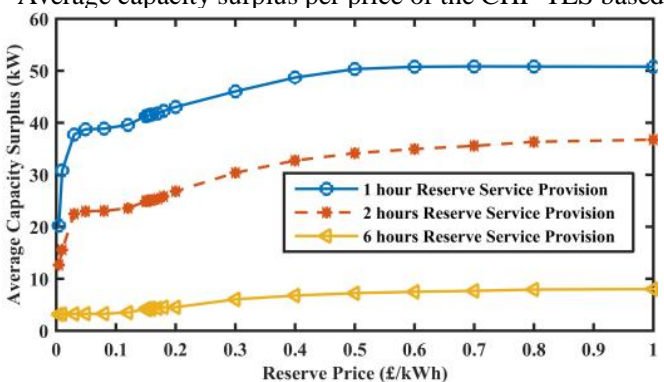

Fig. 5 Average capacity surplus per price of the PV-EES based MG.

reserve price within a range and once outside the range higher reserve prices are no longer able to lead to more capacity contribution from MGs to reserve services.

Similarly, the average capacity contribution from the PVEES based MG is shown in the Fig. 5. It is clear that unlike the CHP-TES based MG, the PV-EES based MG increases its capacity contribution very earlier following the increase of the reserve price and subsequently the capacity contribution would saturate faster than that of the CHP-TES based MG. This can be attributed to the fact that the PV-EES based MG has zero cost when providing reserve services (batteries are charged by PV with no cost). This leads to the earlier sharp increase of the capacity contribution. However, the CHP-TES based MG has fuel cost when providing reserve servces. Thus, the CHP-TES based MG would only provide reserve when the price is over a certain level. Moreover, the capacity contribution to the service lasting 6 hours would not increase much when the reserve price increases. This is due to the fact that the PV-EES based MG is energy-limited, i.e. the energy capacity of EES. In other words, the energy capacity of EES is generally the key constraint for contributing to extreme events related to system resilience.

\section{Cost-benefit Analysis on Storage Size}

In this section, a cost-benefit analysis is performed to study the impact of storage size. The size of the TES and EES in the two MGs were gradually increased and the annual operation cost of the two MGs was calculated. Regarding the CHP-TES based MG, the size of TES was increased from $120 \%$ to $145 \%$ at a step of $5 \%$ in the beginning, and the sizes of $200 \%$ and $300 \%$ were also considered. The investment cost of TES was assumed to be $£ 0.7282 /$ litre [6]. The MG's operation cost was calculated under the reserve price of $£ 1 / \mathrm{kWh}$. As it is presented in the Fig. 6, the total cost of the CHP-TES based MG can reach its minimum total cost when the TES is sized to $263 \mathrm{kWh}$. Further, the TES cost is higher than the total cost in Fig. 6 . This is due to the revenue gained from reserve services resulting in a negative operational cost. However, with the increase of capital investment, the total 


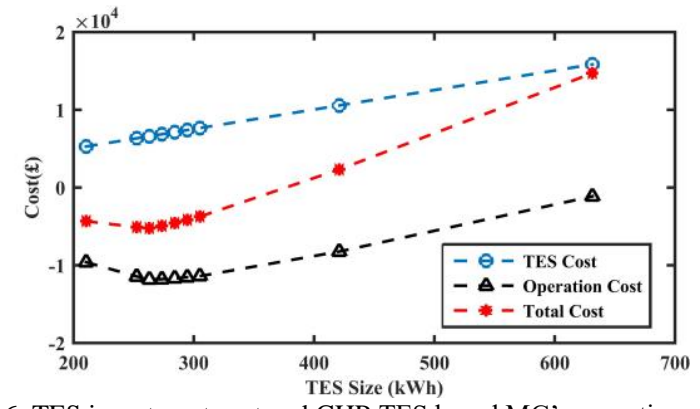

Fig. 6 TES investment cost and CHP-TES based MG's operation cost.

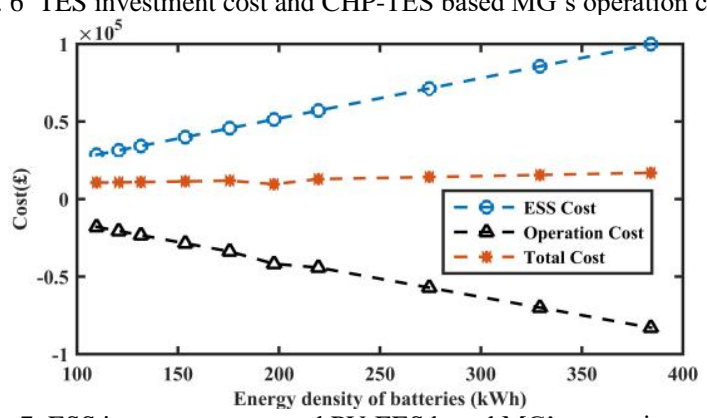

Fig. 7 ESS investment cost and PV-EES based MG's operation cost. cost will become higher than the TES cost.

In terms of the PV-EES based MG, it is assumed that the MG has NAS batteries, with capital cost $£ 260 / \mathrm{kWh}$, whereas the annual operational cost of the PV-EES based MG was calculated under the reserve price of $£ 0.5 / \mathrm{kWh}$. Unlike the CHP-TES based MG, the PV-EES based MG can offset almost all the investment cost for increasing the size of EES by taking part in providing reserve service. This leads to the total cost of the PV-EES based MG increasing slightly when more EES is installed, as presented in Fig. 7. This also demonstrates that the strategic role played by EES in terms of reserve provision. The operational cost of the PV-EES MG can continuously decrease with the increase of EES, owing to EES's capability to shift electriclty consumption. This thus leads to the total cost being lower than the EES cost in Fig. 7.

\section{CONCLUSION}

This paper investigated the techno-economic performance of MGs in the context of providing reserve services becomes a new revenue stream. A co-optimisation technique using stochastic programming has been proposed with the objective to minimise total operational cost, which takes into account the technical constraints of an MG's energy resources, internal energy consumption and uncertainty in the reserve service (e.g., starting time and duration). Without loss of generality, two representative MGs are modelled in the formulation, i.e. one MG with CHP and TES representing dispatchable generation resources, whereas the other one with PV and EES representing renewable but uncontrollable generation resources.

The results show higher reserve prices lead to more capacity contribution, however a clear saturation is observed. Additionally, the capacity contribution to reserve services can be very sensitive to the reserve price varying within certain ranges. The cost-benefit analysis sheds light on the impact of storage size in the techno-economic performance of MGs. In summary, the assessment methodology proposed in this paper can inform the relevant stakeholders and asset owners, energy policy makers and regulators on the microgrids' contribution in reserve service provision as well as their strategic role in a resilient and sustainable energy system.

Future work will focus on the investment and the portfolio optimisation of distributed energy resources in microgrid with consideration of their participation in reserve provision. Moreover, the impact of a wider range of uncertainty (such as forecast errors) will be further investigated.

\section{REFERENCES}

[1] G. Liobikienè and M. Butkus, "The European Union possibilities to achieve targets of Europe 2020 and Paris agreement climate policy," Renewable Energy, vol. 106, pp. 298-309, 2017.

[2] M. Panteli and P. Mancarella, "The Grid: Stronger, Bigger, Smarter?: Presenting a Conceptual Framework of Power System Resilience," IEEE Power and Energy Magazine, vol. 13, no. 3, pp. 58-66, 2015.

[3] "Future Resilience of the UK Electricity System," The Energy Research Partnership (ERP), November 2018.

[4] Y. Zhou, M. Panteli, M. Moreno and P. Mancharella, "System-level Assessment of Reliability and Resilience Provision from Microgrids," Applied Energy, vol. 230, pp. 374-392, 2018.

[5] Z. Li, M. Shahidehpour, F. Aminifar, A. Alabdulwahab and Y. AlTurki, "Networked Microgrids for Enhancing the Power System Resilience," Proc. of the IEEE, vol. 105, no. 7, pp. 1289 - 1310, 2017.

[6] E. A. Martínez Ceseña, N. Good, A. Syrri and P. Mancarella , "Technoeconomic and business case assessment of multi-energy microgrids with co-optimization of energy, reserve and reliability services," Applied Energy, vol. 210, pp. 896-913, 2018.

[7] A. Syrri, et al, "Contribution of Microgrids to distribution network reliability," 2015 IEEE Eindhoven PowerTech, pp. 1-6, 2015.

[8] Z. Wang and J. Wang, "Self-Healing Resilient Distribution Systems Based on Sectionalization Into Microgrids," IEEE Transactions on Power Systems, vol. 30, no. 6, pp. 3139 - 3149, 2015.

[9] C. Chen , J. Wang, F. Qiu and D. Zhao, "Resilient Distribution System by Microgrids Formation After Natural Disasters," IEEE Transactions on Smart Grid, vol. 7, no. 2, pp. 958 - 966, 2015.

[10] C. Chen, J. Wang and D. Ton, "Modernizing Distribution System Restoration to Achieve Grid Resiliency Against Extreme Weather Events: An Integrated Solution," Procs of the IEEE, vol. 105, no. 7, pp. $1267-1288,2017$

[11] N. Good, E. A. Martínez Ceseña and P. Mancarella, "Ten Questions Concerning Smart Districts," Building and Environment, vol. 118, pp. 362-376, 2017.

[12] A. Frosinou, "Techno-economical assessment for optimal sizing of energy storage in microgrids under normal and contingency operation conditions," The University of Manchester, Manchester, 2018.

[13] National Grid, "STOR Market Info for TR24 - Appendix," 2015.

[14] P. Mancarella, "MES (multi-energy systems): An overview of concepts and evaluation models," Energy, vol. 65, pp. 1-17, 2014.

[15] P. Mancarella, et al, "Modelling of integrated multi-energy systems: Drivers, requirements, and opportunities," In Procs. of the 2016 IEEE Power Syst. Comput. Conf., Genoa, Italy, 20-24 June 2016.

[16] L. N. Ochoa, F. Pilo, A. Keane, P. Cuffe and G. Pisano, "Embracing an Adaptable, Flexible Posture: Ensuring That Future European Distribution Networks Are Ready for More Active Roles," IEEE Power and Energy Magazine, vol. 14, no. 5, pp. 16-28, 2016.

[17] F. Shariatzadeh, C. B. Vellaithurai, S. S. Biswas, R. Zamora and A. K. Srivastava, "Real-Time Implementation of Intelligent Reconfiguration Algorithm for Microgrid," IEEE Transactions on Sustainable Energy, vol. 5, no. 2, pp. 598 - 607, 2014.

[18] S. Conti, S. A. Rizzo, E. F. El-Saadany, M. Essam and Y. M. Atwa, "Reliability Assessment of Distribution Systems Considering Telecontrolled Switches and Microgrids," IEEE Transactions on Power Systems, vol. 29, no. 2, pp. 598 - 607, 2014.

[19] O. Olatujoye, F. J. Ardakani, A. J. Ardakani and J. McCalley, "Cooptimization in power systems," in Proc. 2017 North American Power Symposium (NAPS), Morgantown, WV, 2017, pp. 1-6. 